\title{
Is there still a use for sonographic fetal evaluation in the era of widespread noninvasive prenatal
} tests?

\section{Joseph Hasson \\ Igal Wolman}

Ultrasound Unit in Obstetrics and Gynecology, Lis Maternity Hospital, Tel-Aviv Medical Center, Tel Aviv, Israel
Correspondence: Igal Wolman Ultrasound Unit in Obstetrics and Gynecology, Lis Maternity Hospital,TelAviv Medical Center, Tel Aviv 64239, Israel Emaildrwolmanc@gmail.com
This article was published in the following Dove Press journal:

Research and Reports in Focused Ultrasound

I October 2013

Number of times this article has been viewed

The second trimester ultrasound examination evaluates the fetus for structural malformations, and also searches for sonographic markers of fetal Down syndrome. The main markers include increased nuchal fold, short humerus and femur, echogenic intracardiac focus, pyelectasis, hyperechoic bowel, and any major abnormality. The absence of any marker reflects a $60 \%-80 \%$ reduction in the prior risk of trisomy 21 based on advanced maternal age or serum marker screening risk. ${ }^{1}$ The presence of sonographic markers, either singly or in combination, raises the baseline risk as calculated for each individual marker. Many studies have attempted to establish the sensitivity and specificity of these various ultrasonographic markers in order to allow adjusting the risk for trisomy 21 , and therefore the need for genetic amniocentesis, depending on the presence or absence of these markers. Some found the average sensitivity of these markers to be $31 \%$ for short femur, $33 \%$ for short humerus, $32 \%$ for short femur and humerus, $32 \%$ for nuchal fold thickening, $7 \%$ for echogenic bowel, and $71 \%$ for short ear length. ${ }^{2}$ Nicolaides also addressed the performance of screening tests for trisomy $21{ }^{3}$ He combined data from two major series and published the following likelihood ratio for Down syndrome according to the presence of the sonographic markers as follows: nuchal fold 9.8; short humerus 4.1; short femur 1.6; hydronephrosis 1.0; echogenic focus 1.1; echogenic bowel 3.0; and any major defect 5.2. ${ }^{3}$

A recent meta-analysis ${ }^{4}$ published in the Journal of Ultrasound in Obstetrics and Gynecology evaluated the accumulated data on the screening performance of second trimester sonographic markers for fetal trisomy 21. All studies between 1995 and September 2012 that provided data on the incidence of sonographic markers in trisomy 21 and euploid fetuses at 14-24 weeks' gestation were reviewed, and the detection rate, false positive rate, and positive and negative likelihood ratios of markers were calculated. This comprehensive meta-analysis found pooled estimates of positive and negative likelihood ratios for Down syndrome to be, respectively: 5.8 and 0.8 for intracardiac echogenic focus; 27.5 and 0.9 for ventriculomegaly; 23.3 and 0.8 for increased nuchal fold; 11.4 and 0.9 for hyperechogenic bowel; 7.6 and 0.9 for mild hydronephrosis; 3.7 and 0.8 for short femur; 4.8 and 0.7 for short humerus; 21.5 and 0.7 for aberrant right subclavian artery; and 23.2 and 0.4 for absent or hypoplastic nasal bone. The combined negative likelihood ratio, obtained by multiplying the values of individual markers, was 0.13 when short femur but not short humerus was included and 0.12 when short humerus but not short femur was included. 
The clinical implications of this meta-analysis are that, if it is possible to conduct a systematic second trimester ultrasound examination which demonstrates the absence of all of these major defects and markers, there is a 7.7-fold reduction in the risk for trisomy 21 . It should be noted that the detection of any one of the markers during the scan should stimulate the sonographer to look for all other markers or defects as well. Another major conclusion of this meta-analysis is that, in the case of most isolated markers, including intracardiac echogenic focus, echogenic bowel, mild hydronephrosis, and short femur, there is only a small effect on modifying the pretest odds ratio for Down syndrome.

In recent years, both the research on noninvasive prenatal testing (NIPT) of fetal trisomy 21 and its clinical use have been developing rapidly. Commercial tests for detecting free fetal DNA in maternal blood have become available, although the costs are still beyond reach for many pregnant women. A recent review ${ }^{5}$ found NIPT to be a promising test with sensitivity approaching $100 \%$, which may likely replace the prenatal serum screening test that is currently combined with nuchal translucency measurement in the first trimester of pregnancy. It would thus seem that we are wasting a lot of effort in training specialists to perform elaborate fetal evaluation scans while a simple blood test can provide us with a more accurate diagnosis. The question is whether, in the presence of such a simple noninvasive and accurate test for the detection of trisomy 21, there is still a place for these elaborate examinations.

Still, before NIPT can be introduced as a screening test, more evidence is needed from large prospective accuracy studies, and the question of cost-effectiveness and justification of performing NIPT for every pregnant woman remains unanswered. Ultrasound has become an integral part of the follow-up of pregnancy and is widely available. Most physicians are trained in performing the nuchal translucency examination. Furthermore, NIPT is still a very expensive test. Thus, ultrasonographic fetal evaluation remains a much more accessible, cost-effective, and relevant examination for most pregnant women in the world.

The cited meta-analysis emphasizes the fact that, in skilled hands, ultrasonographic fetal evaluation may be a reliable screening tool for detecting high-risk patients who may benefit from invasive prenatal testing which can include chromosomal microarray analysis in addition to traditional chromosomal analysis. Obviously, it is essential that those performing the second trimester scan receive appropriate training and certification of competence, and subject their results to regular and constant audit. In such conditions, it may be too early to abandon ultrasonographic fetal evaluation as a powerful screening tool.

\section{Disclosure}

The authors report no conflicts of interest in this work.

\section{References}

1. Benacerraf BR. The role of the second trimester genetic sonogram in screening for fetal Down syndrome. Semin Perinatol. 2005;29:386-394.

2. Vintzileos AM, Egan JF. Adjusting the risk for trisomy 21 on the basis of second-trimester ultrasonography. Am J Obstet Gynecol. 1995; 172:837-844.

3. Nicolaides KH. Screening for chromosomal defects. Ultrasound Obstet Gynecol. 2003;21:313-321.

4. Agathokleous M, Chaveeva P, Poon LC, Kosinski P, Nicolaides KH. Meta-analysis of second-trimester markers for trisomy 21. Ultrasound Obstet Gynecol. 2013;41:247-261.

5. Mersy E, Smits LJ, van Winden LA, de Die-Smulders CE; South-East Netherlands NIPT Consortium. Noninvasive detection of fetal trisomy 21: systematic review and report of quality and outcomes of diagnostic accuracy studies performed between 1997 and 2012. Hum Reprod Update. 2013;19(4):318-329.
Research and Reports in Focused Ultrasound

\section{Publish your work in this journal}

Research and Reports in Focused Ultrasound is an international, peerreviewed, open access online journal publishing original research, study protocols, reports, editorials, reviews and commentaries on all aspects of focused ultrasound technologies for the treatment of cancer and other diseases. The manuscript management system is completely

\section{Dovepress}

online and includes a very quick and fair peer-review system, which is all easy to use. Visit http://www.dovepress.com/testimonials.php to read real quotes from published authors. 